Int. J. Dev. Biol. 51: 273-281 (2007)

doi: $10.1387 / \mathrm{ijdb} .062249 \mathrm{ep}$

Original Article

\title{
Analysis of a new allele of limb deformity (Id) reveals tissue- and age-specific transcriptional effects of the Ld Global Control Region
}

\author{
EMILIA PAVEL' ${ }^{1}$ WENNING ZHAO ${ }^{1}$, KIMERLY A. POWELL ${ }^{2}$, MICHAEL WEINSTEIN $^{3}$ \\ and LAWRENCE S. KIRSCHNER*,1,4
}

\begin{abstract}
${ }^{1}$ Department of Molecular Virology, Immunology and Molecular Genetics, The Ohio State University, Columbus, ${ }^{2}$ Department of Biomedical Engineering, The Orthopaedic Research Center, Lerner Research Institute of The Cleveland Clinic Foundation, Cleveland, ${ }^{3}$ Department of Molecular Genetics, The Ohio State University, Columbus and ${ }^{4}$ Division of Endocrinology, Diabetes and Metabolism, Department of Internal Medicine, The Ohio State University, Columbus, $\mathrm{OH}, \mathrm{USA}$.
\end{abstract}

\begin{abstract}
The mouse limb deformity (Id) phenotype is characterized by developmental failure of distal limb structures often associated with renal anomalies. It is caused by loss of the BMPantagonist Gremlin in the limb buds, either through mutation of Grem1, or by loss of a transcriptional global control region (GCR) located in the neighboring Fmn1 gene. In this report, we describe a new allele of $I d$ due to complete deletion of Fmn1, including its GCR. Unlike many other Id strains, these mice are viable and fertile as homozygotes. As expected, this genomic deletion causes loss of Gremlin in the developing limb buds, but effects in other tissues are variable. Specifically, Grem 1 expression is retained in the developing lung and kidney, whereas expression is lost from the corresponding adult tissues. In contrast, expression in the brain appears to be unaffected by loss of the GCR. To provide information about long-range transcriptional effects of this region, effects of the deletion on the transcription of neighboring genes were also investigated. This analysis revealed that alterations in neighboring genes do occur, but only in a limited fashion. These data indicate that the predominant effect of the Ld GCR is to activate the expression of Grem 1 in the developing limb buds, although it may serve a minor role in longrange transcriptional effects that extend beyond Fmn 1 and Grem 1.
\end{abstract}

KEY WORDS: limb development, global control region, gremlin, formin, transcriptional control

\section{Introduction}

The formation of the vertebrate limb illustrates an important paradigm in development, as it involves distinct transcriptional and signaling programs along each of the three axes, proximaldistal, dorsal-ventral and anterior-posterior (Niswander, 2000). Detailed characterization of this process has been carried out at multiple levels, including genetic, biochemical and functional; these studies have focused on multiple systems, including predominantly the mouse and chick (for reviews, see Gurrieri et al., 2002, Mariani and Martin, 2003, Tickle, 2003, Stopper and Wagner, 2005). From a genetic standpoint, there are a small number of mouse single gene mutants that have proved suitable for the analysis of mouse limb development, including mutants such as extra-toes (Gli3), brachypodism (Gdf5), syndactylism (Serrate2) and mutations affecting members of the Hox genes such as synpolydactyly (Hoxd13) (reviewed in Gurrieri et al., 2002, Zelzer and Olsen, 2003). There are also other genes shown to be crucial for limb development such as Trp63 or Sonic hedgehog (Shh), although mice lacking these genes are not viable (Mills et al., 1999, Yang et al., 1999, Niedermaier etal., 2005). Tissue specific knockouts such as those generated using Msx2-cre (Sun et al., 2000) have provided another means for investigation and confirmation of important signaling pathways affecting limb development, as these mice can often circumvent embryonic lethality caused by global gene disruption (Pan et al., 2005).

Abbreviations used in this paper: BMP, bone morphogenic protein; FGF, fibroblast growth factor; GCR, global control region; ld, limb deformity; qRT-PCR, quantitative real-time PCR; Shh, sonic hedgehog.

*Address correspondence to: Lawrence S. Kirschner. 544 TMRF, 420 W 12th Ave, Columbus, OH 43210, USA. Fax:+1-614-688-4006.

e-mail: Lawrence.Kirschner@osumc.edu

Electronic Supplementary Material: This article is accompanied by an audio PodCast, which can be downloaded from: http://dx.doi.org/10.1387/ijdb.062249ep 

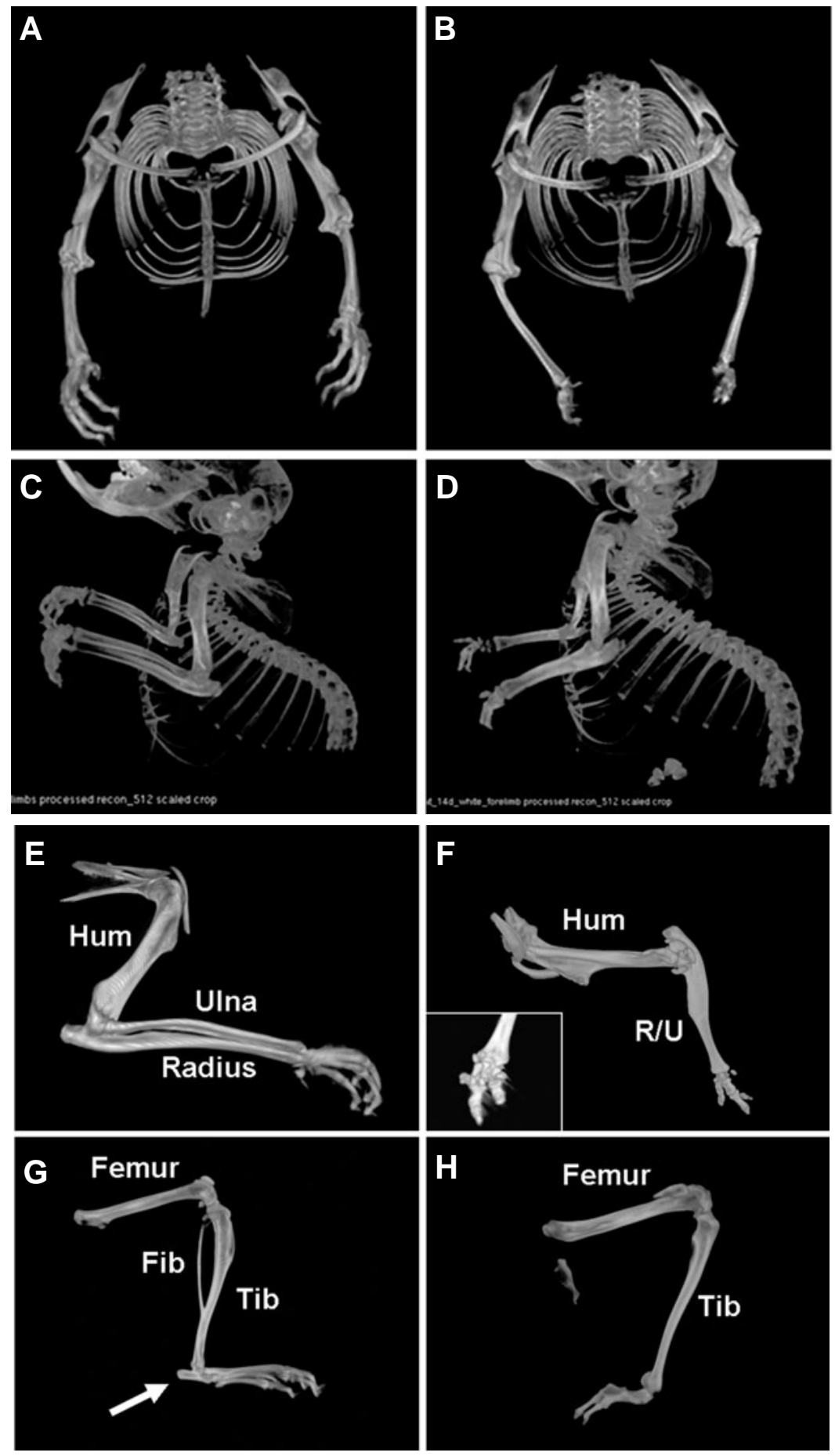

Fig. 1. MicroCT imaging of $I \boldsymbol{d}^{\mathrm{h} \mathbf{L S K}}$ mice. (A,B) Images of the upper torso of 6 -wk old heterozygote and mutant animals taken from a superior view after removal of the head. (C,D) Lateral images of the upper body of P14 heterozygote and mutant animals. Note that the bony abnormalities are confined to the distal limb and paw structures. (E-H) Images of upper $(\mathbf{E}, \mathbf{F})$ and lower $(\mathbf{G}, \mathbf{H})$ extremities from 6 month old heterozygote $(E, G)$ and mutant $(F, H)$ animals. In the upper limb, note the fusion of the radius and ulna $(R / U)$ and failure of development of the distal paw structures. The inset in panel (F) shows a typical paw structure, with 3 rudimentary digit structures. In the lower limb, note the absence of the fibula and the calcaneus (arrow in Panel G) in the mutant, as well as the malrotation of the paw.
One of the single gene mutations whose alleles have been studied extensively is the limb deformity (/d) phenotype, which was initially described in the 1960's as a spontaneously arising autosomal recessive mutation. Since its initial description, several alleles have been isolated, either spontaneously or through insertional or radiation-induced mutagenesis (reviewed in Wang et al., 1997). These mice have foreshortening of the distal appendages, both upper and lower, including fusion of distal limb bones and malformation of the paws. Through genetic mapping of the induced mutations, the genetic locus for $/ d$ was localized to mouse chromosome 2 and eventually mutations were detected within the Fmn 1 gene (Maas et al., 1990, Woychik et al., 1990). This gene, spanning almost $400 \mathrm{~kb}$, encodes Formin1, a member of a small family of large proteins thought to be important for cell polarity and motility (Zeller et al., 1999). In addition to the limb defects, /d mice also variably exhibited defects in renal formation, so that many strains die after birth from failure of kidney development (Maas et al., 1994).

Although the genetic lesions were found to reside within the Fmn1 structural gene, follow-up studies, including targeted knockout of Fmn1, did not recapitulate the /d limb phenotype (Zeller et al., 1999). Around the same time, careful analysis of distal limb specification revealed the need for the establishment of a feedback loop involving fibroblast growth factor (FGF) and Sonic hedgehog (Shh) in the proper development of distal limb structures and that the /d mutants displayed a disruption in this process (Haramis et al., 1995). The role of bone morphogenic proteins (BMPs) and the Gremlin protein, a BMP antagonist of the Cerberus/Dan family (Topol et al., 1997, Pearce et al., 1999) was noted to be crucial in these interactions (Capdevila et al., 1999, Zuniga et al., 1999). Knockout of Grem1 (Khokha et al., 2003, Michos et al., 2004) demonstrated that mice exhibited a limb and kidney phenotype similar to that of the /dmice. It was subsequently shown in an elegant series of experiments (Zuniga et al., 2004) that the Fmn1gene mutations in $/ d$ mice led to a failure of Gremlin1 expression in embryonic limb buds. Furthermore, two of the previously uncharacterized /d mutants were found to be mutations directly affecting Grem 1through other means. These findings suggested that the mutations in Fmn1 caused deletion of a Global control region (GCR) affecting limb development, leading to a failure of Grem1 expression and the /dphenotype.

In this manuscript, we present data on a new, spontaneous allele of $/ d$ and show that this allele is, in fact, a deletion of the entire Fmn 1 gene. In order to understand the effects of loss of the $\angle d G C R$, we have tested the expression of Gremlin1 in other tissues, as well as studied the effects of this mutation on the expression of neighboring genes. These data reveal that the major role of the $L d G C R$ is to regulate the expression of the Grem1gene in the developing limb, 
although it also exerts subtle effects on other genes within this chromosomal environment.

\section{Results}

\section{Characterization of the phenotype}

During the course of a transgenic project, we noticed that a small number of pups were born with obvious limb deformities (Fig. 1). Because the number of mouse mutants with similar deformities is quite small (Gurrieri et al., 2002), we decided to further characterize the phenotype and to identify the causative genetic locus. Through breeding studies, we determined that the locus was inherited as an autosomal recessive trait. Although the mutant pups were smaller than non-mutant littermates, the distribution of the offspring from mutant $x$ heterozygote crosses was not different from predicted by Mendelian inheritance (data not shown).

In order to characterize the phenotype better, we observed the mice for over 18 months, with no excess mortality detected (data not shown). MicroCT of mutants of varying ages revealed that the developmental anomaly was confined to the distal limbs, but that development of the axial skeleton, the limb girdle and proximal long bones was unremarkable (Fig. 1 A-D). In the upper extremity, there was fusion of the radius and ulna, with variably formed paw structures, typically comprised of 3 rudimentary digits (Fig. 1F). In the lower limb, there was shortening of the tibia and complete absence of the fibula in all mice examined. It was frequently observed that the paws of the lower extremities were malrotated (Fig. $1 \mathrm{H}$ ). These changes were detectable in the embryos by e12.5, but mutants were not distinguishable by morphologic changes at e10.5 (data not shown).

\section{Identification of the mutation as an allele of the Id phenotype}

At this juncture in our studies, we became aware that a similar phenotype had previously been described in the 1960's and named the limb deformity (Id) mutant (see Kleinebrecht et al., 1982). Previous genetic mapping of other /d strains obtained through insertion mutagenesis (Woychik et al., 1985, Messing et al., 1990) or radiation-induced chromosomal breaks (Woychik et al., 1990) had localized these causative mutations to the Fmn1 gene on mouse chromosome 2 (Wang et al., 1997). However,

\section{TABLE 1}

\section{PRIMERS FOR GENOMIC AND cDNA AMPLIFICATION}

\begin{tabular}{|c|c|}
\hline & Left \\
\hline \multicolumn{2}{|l|}{ Genomic Primers } \\
\hline Ryr3 & GCGAGGATGAGATCCAGTTC \\
\hline 4930563p21 & СТСТGTССССАТССССТАAG \\
\hline FMN 40M from 3' & GTTACACGTGGCACCCTTTT \\
\hline FMN 3' end & GGACCCTGGGATAGATGGTT \\
\hline Grem1 & TCATTGTGCTGAGCCTTGTC \\
\hline Sgne1 & GCTGGTGAATGACTGGGTTT \\
\hline \multicolumn{2}{|l|}{ cDNA primers } \\
\hline Fmn1 & GACTCCAGGCAGACTCCAAG \\
\hline Grem1 & ACTCGTCCACAGCGAAGAAC \\
\hline 4930563p21 & CCGGGATCAACTCTGGTAGA \\
\hline Ryr3 & GCGAGGATGAGATCCAGTTC \\
\hline Gja9 & ACTGCCCAGTCTTTGTCTGC \\
\hline Sgne1 & GAGTTCAGCCGAGAATTCCA \\
\hline Arhfgap11a & GAGTTCAGCCGAGAATTCCA \\
\hline Gapdh & GCAAATTCAACGGCACAGTCAAG \\
\hline
\end{tabular}

Right

GAGTGTGAGGTGGCAGCAC CAGGGTGTCCACGAGAAAG GCACTTTCCTGGCTCAGACT TTTGTTTGCTTGCTTCGTTG GAATCGCACCGCATACACT CTTAAGCTGGGGTGGTGGTA

CCGGATGTGAAATGTCTTGA TCATTGTGCTGAGCCTTGTC CAGGGTGTCCACGAGAAAGT GGACTGTTCCAGCACGAAAT TCGTACACCGTCTCCCCTAC TTGCCACAACATTGTCCAAC TTGCCACAACATTGTCCAAC GTTCACACCCATCACAAACATGG
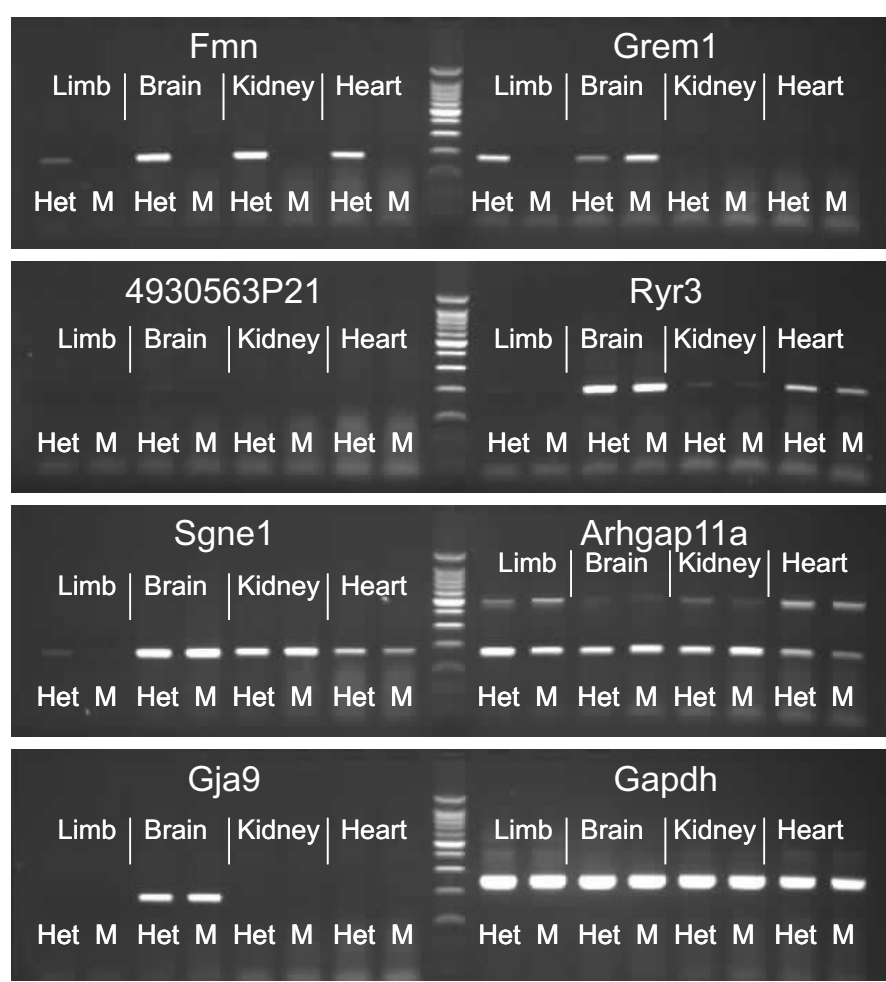

Fig. 2. Semi-quantitative RT-PCR analysis of transcriptional changes in Id $\mathbf{I}^{\text {LSK }}$ mice. mRNA was isolated from heterozygote (Het) or mutant (M) e12.5 limb buds and from adult brain, kidney and heart and analyzed for expression of 7 genes in the region of the Fmn1-Grem1 locus on chromosome 2. Note that expression of Formin is lost in all tissues tested, whereas expression of Gremlin is lost in the limb buds, but not the brain. Gene expression for the other transcripts is variably affected in this semi-quantitative assay.

recent analysis of the / $d$ phenotype had indicated that loss of Formin 1 itself was not the causative event in the phenotype; rather, the limb mutant phenotype was due to loss of expression of the nearby Grem1 gene, encoding the BMP antagonist Gremlin/Drm (Zuniga et al., 2004). This was confirmed by the generation of a truncated deletion mutation of Formin 1 or by identification of a failure of Grem1 expression in two other alleles of $l d, l^{d}$ and $/ d^{\mathrm{OR}}$ (Zuniga et al., 2004)

To determine if our spontaneous mutant exhibited a decrease in Grem 1 expression, we isolated limb buds from e12.5 embryos and performed semi-quantitative RT-PCR for Fmn1 and Grem1 expression. These studies showed that neither gene transcript was detectable in embryonic limb buds, although Grem1 was clearly detected by this method in samples from the brain (Fig. 2). We took these data to indicate that our mutant was a new, spontaneously-arising allele of the $/ d$ phenotype, which we name $/ d^{\text {LSK }}$.

Because $/ d$ has frequently been associated with renal agenesis (Maas et al., 1994), we undertook a survey of mice to determine the frequency of this anomaly in our strain. Of 20 mice examined, we observed unilateral renal agenesis in 1 mouse, indicating that this aspect of the phenotype is less common in our 


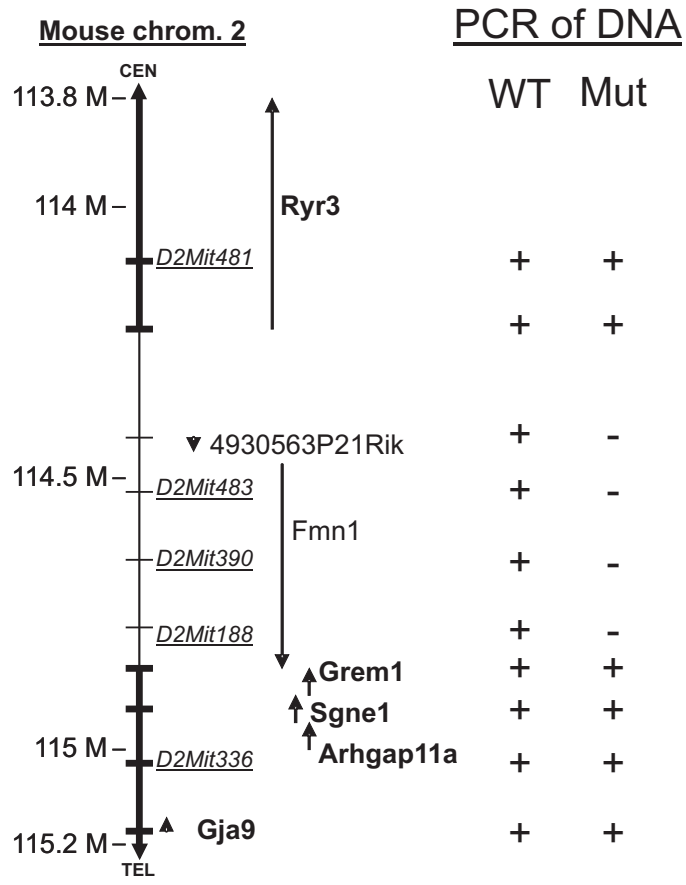

Fig. 3. Analysis of the gene deletion in Id ${ }^{\text {LSKK }}$ mice. A schematic diagram of chromosome 2 is shown to scale (left), with the location of tested markers and genes indicated. The right side shows a summary of the results of genomic PCR from comparing phenotypically normal to mutant animals (right). All samples were run in duplicate. The scale to the left indicates sequence distance from the centromere of chromosome 2. The thin portion of the line indicates the region of the deletion. Note that 2 additional Fmn1 intragenic markers between D2Mit188 and Grem 1 were also tested (Fmn 3' and Fmn 40K from 3', see Table 1) and found to be missing in the mutants. These data indicate that the $\mathrm{Id}^{1 L S K}$ mice carry a deletion of the entire Fmn 1 gene and the 4930563P21 Riken gene prediction.

allele than in others. Examination of the kidneys from adult mice revealed no abnormality at the histologic level (data not shown). The mutation was initially detected on a mixed genetic background, which included contributions from $129 / \mathrm{SvJ}, \mathrm{C} 57 \mathrm{BI} / 6$ and FVB. The mutation was backcrossed for 5 generations into a BALB/c background, with no significant change in the phenotype, from which it was maintained by sibling intercrosses.

\section{Genetic characterization of the mutation}

Prior to this report, there were 7 other reported alleles of the /d phenotype (see Wang et al., 1997, Ward-Bailey etal., 2006). Four of these arose spontaneously $\left(/ d^{\mathrm{OR}}, / d^{\mathrm{d}}, / d^{2 \mathrm{~J}}\right.$ and $\left./ d^{\beta \mathrm{J}}\right)$, whereas two were induced by transgene insertion ( $/ d^{\top \mathrm{gBri137}}$ and $\left./ d^{\top \mathrm{gHd}}\right)$ and one was a radiation-induced rearrangement $\left(/ d^{\mathrm{m} 2}\right)$. Of the 4 spontaneous alleles, the $10^{\mathrm{OR}}$ allele was found to be due to a spontaneous $12.7 \mathrm{~kb}$ deletion encompassing Grem1, whereas the $/ d$ allele was found to be a point mutation affecting Grem 1 splicing (Zuniga et al., 2004). In our mice, because we did not observe transcripts of either Fmn1 or Grem1 in the limb buds, we suspected that our allele would involve the Fmn1 locus. To evaluate this possibility, genomic DNA from mutants and control animals was subject to PCR amplification using primers from the
Fmn1 and Grem1 genes. Our initial analysis demonstrated that both exons of Grem 1 were intact, but that polymorphic markers located with the Fmn1 gene were missing from the mutants (Fig. $3)$. In order to determine the extent of this deletion, additional primer sets were generated both proximal and distal to the Fmn1 gene (Table 1). This analysis demonstrated that the deletion in the $/ d^{\mathrm{L}} \mathrm{LSK}$ allele encompassed the entire Fmnl gene, as well as the anonymous EST 4930563P21. The next gene on the centromeric side, Ryr3 (Ryanodine receptor 3) appeared intact, as did all genes telomeric to Grem1. In order to define if there were any residual portions of the Fmn1 gene present, we designed additional primer sets at the 3' end of the gene. Neither primers $40 \mathrm{~kb}$ from the 3' end nor primers located in the most 3' exon amplified a fragment from mutant mice. Comparison of this data to the mouse genomic sequence map indicates that the deletion spans at least $400 \mathrm{~kb}$ of DNA and includes the entirety of the Fmn1gene. The telomeric breakpoint between Fmn1 and Grem 1 is localized to an area of approximately $40 \mathrm{~kb}$, although the exact location has not been determined.

\section{Expression changes associated with loss of the Fmn1 gene}

The 3' of the Fmn1gene has been shown to contain a locus that controls expression of the Fmn1 and Grem1 gene in the limb buds, despite the fact that this region is located $>200 \mathrm{~kb}$ from the Fmn 1 promoter and $>100 \mathrm{~kb}$ from the Grem 1 promoter (Zuniga, 2005). In order to determine if loss of this region affects the transcription of other genes in the area, as is commonly observed in long-range control elements (Kleinjan and van Heyningen, 2005) we performed RT-PCR analysis on the genes located in this region. For these studies, the mice analyzed were littermates from a mutant $x$ heterozygote cross, so that mice are either homo- or heterozygotes for the mutation.

As a first step, we performed semi-quantitative RT-PCR using a pooled sample of e12.5 limb buds and mRNA from the adult brain, kidney and heart. As shown in Fig. 2, no expression of Formin1 message was detected in any tissue. Although Gremlin expression was notably absent from the limb buds, expression in the brain was retained. This assay did not show significant expression of Gremlin in the adult kidney or the heart. Genes centromeric to Fmn1 included the deleted EST 4930563P21, whose expression was not detected in the heterozygotes or mutants and Ryr3, which was detected in the brain and heart at levels unchanged between mutants and heterozygotes. Of the genes tested telomeric to Grem1, Sgne1 (recently renamed Scg5)expression appeared to be diminished only in the limbs, but the levels were quite low. No changes were observed in the expression or tissue distribution of Arhgap11a (Rho GTPase activating protein 11A, previously known as 6530401L4) or Gja9, the gap junction membrane channel protein $\alpha 9$.

To obtain a better understanding of organism-wide alterations in gene expression, we next performed quantitative RT-PCR (qRT-PCR) on tissues from a pair of adult male and female animals. Because we had not detected any expression changes in genes centromeric to Fmn1 (specifically Ryr3) by semi-quantitative analysis, we decided to focus on Grem 1 and the two genes telomeric to it, Sgne1 and Arhgap11a. As shown in Fig. 4, Grem1 expression was notably absent in the kidneys from both male and female mutant animals, despite the lack of a renal phenotype. Gremlin has also been reported to be expressed in the lungs and 
to be required for lung branching morphogenesis (Lu et al., 2001, Shi et al., 2001). Although levels were easily detected in the heterozygotes, no expression was detected in the mutant lungs, despite the fact that no lung abnormalities were observed (data not shown). Similar to previous reports (Topol et al., 1997), we also detected expression of Grem 1 in the brain and kidney, but not in the heart or liver. We also detected a discrepancy in the expression of Grem 1 in the pituitary glands of male mice, with easily detectable levels in heterozygotes but not in the mutants. Female mice did not express Grem1 in the pituitary.

Sgne1, the gene telomeric to Grem1, encodes a protein thought to be important for neuroendocrine peptide hormone processing (Westphal et al., 1999). This gene has previously been shown to be expressed in the pituitary and other tissues, with minimal expression in other tissues (Iguchi et al., 1984). In agreement with these prior studies, we found that this gene was highly expressed in the pituitary and there appeared to be a loss of expression in the mutant animals. Although expression was detectable in whole brain, adrenal gland and at low levels in the kidney, no differences were observed between mutants and heterozygote mice.

We continued our analysis to include Arhgap11a, which lies adjacent to Sgne1 on the distal side from Grem1. Expression of this gene was detectable in all tissues, although levels were very low in skeletal muscle. Similar to Grem1, we noted a decreased expression of this gene in the pituitary glands of mice of both sexes. For all other tissues tested, there did not appear to be significant differences in expression in the mutants compared to the controls.

In order to eliminate effects caused by variations in gene expression in individual mice, qRT-PCR was performed from an additional 4 mice per group (5 mice total per group). Because our initial data indicated that Grem1 was expressed at significant levels in only 4 tissues (kidney, lung, brain, pituitary) and these
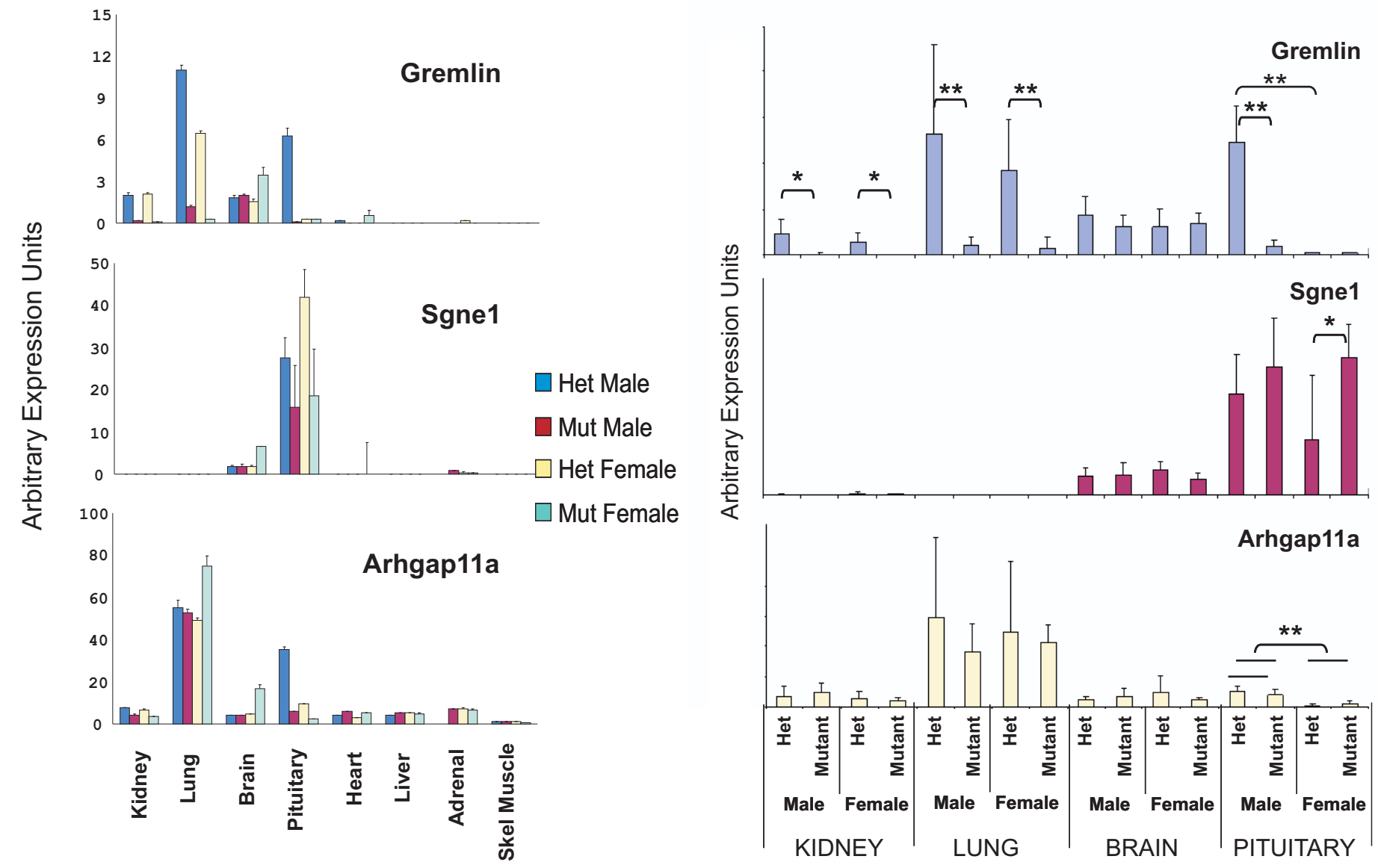

Fig. 4 (Left). Survey analysis of quantitative RT-PCR of Grem1, Sgne1 and Arhgap11a in Id ${ }^{\text {1LSK }}$ mice. mRNA was isolated from a heterozygote (Het) or mutant (Mut) adult male and adult female from the tissues indicated and analyzed by qRT-PCR as described in Materials and Methods. All data is presented as expression relative to Gapdh, which was normalized to $10^{5}$ expression units. Note that the Sgne 1 data is in thousands of units. Gremlin is expressed only in 4 tissues (kidney, lung, brain and pituitary) with clear reduction in both kidney and lung, but no alterations in brain and potentially sex-specific changes in pituitary.

Fig. 5 (Right). Quantitative RT-PCR analysis of Grem1, Sgne1 and Arhgap11a in Id ${ }^{1 L S K}$ mice in kidney, lung, brain and pituitary. $m R N A$ waS isolated from heterozygote (Het) or mutant (Mut) adult males ( $N=5$ for each group) and adult females ( $N=5$ for each group) from the tissues indicated and analyzed by $q R T$-PCR as described in Fig. $4 .{ }^{*}: p<0.05$ between groups. ${ }^{*}: p<0.01$ between groups, by unpaired 2 -tailed Student $t$-test. Gremlin expression is retained in mutant brains, but is lost in kidney and lung; reduction in the pituitary occurs only in male mice. Also note the sexually dimorphic changes in the expression of Sgne1 and Arhgap11a observed in the pituitary gland. 
same tissues appeared to exhibit changes in the other transcripts, we focused the in-depth analysis on these 4 tissues, studying the expression of Grem1, Sgne1 and Arhgap11a (and Gapdh as a normalization control). This study confirmed that Gremlin is essentially absent from mutant kidney, lung and pituitary, whereas expression in brain is unaffected (Fig. 5, top). This analysis also confirmed the sex-specific expression of Grem 1 in the pituitary; it is present in moderate levels in of males but is essentially absent from this gland in females. Interestingly, we also found that Arghap 1 1a exhibits the same pattern of sex-specific expression, although there is no effect of the mutation in this phenomenon. In contrast to the initial set of mice, we observed in this larger group of mice that expression of Sgne1 appeared to be increased in the mutant animals. This reached statistical significance in the females $(p<0.05)$, but not the males, making the biological significance unclear.

As shown above, the data indicated that the mutant mice did not express Grem1 in the adult kidney or lung, despite the lack of a phenotype affecting these organs (data not shown). To determine if Gremlin expression was present during embryogenesis, mRNA was prepared from the limb buds, upper body (containing the developing lung) and lower body (containing the developing kidneys) of heterozygote or mutant animals at e11.5. Although we did not prepare mRNA from isolated embryonic kidneys or lungs, our data (Fig. 4) and that of others (Topol et al., 1997, Michos et al., 2004) suggest that the kidneys and lungs are the only organs (outside of the limb buds) that express Gremlin in the lower and upper body halves, respectively. Expression of Fmn 1 and Grem 1 were assayed by semi-quantitative PCR from these tissues (Fig.

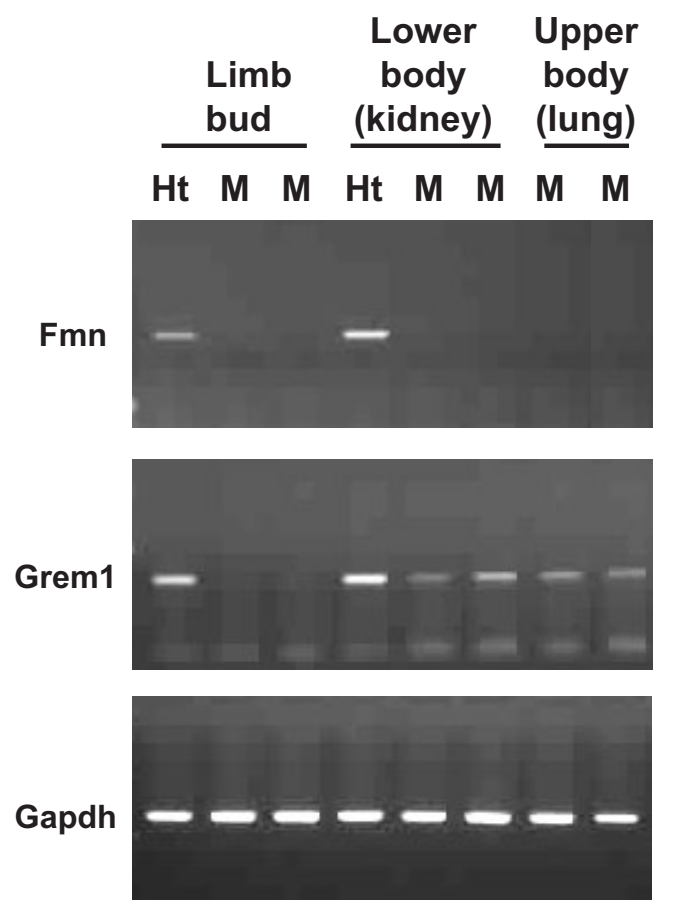

Fig. 6. Semi-quantitative RT-PCR analysis of Fmn1 and Grem1 in developing kidney and lung in $\boldsymbol{I d}^{\mathbf{1} \mathbf{L S} \boldsymbol{K}}$ mice. mRNA was isolated from e11.5 embryos from heterozygote $(\mathbf{H t})$ or mutant $\mathbf{( M )}$ mice and analyzed by RT-PCR as described in Materials and Methods. These data indicate that expression of Gremlin is retained in the developing kidney and lungs.
6). As expected, Fmn1transcripts were not detected in any tissue. As in Fig. 2, no Grem 1 message was amplified from limb buds, although an easily detected signal was seen in both the lower and upper body halves, which we interpret as showing that Grem1 expression was retained in the embryonic kidneys and lungs.

\section{Discussion}

In this report, we present the isolation and clinical characterization of a new allele of the /dphenotype, which we designate $/ d^{\text {LSK }}$

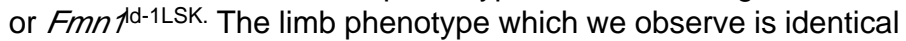
to other previously described /d mutants, consisting of defects of the distal portions of both the upper and lower limbs. The renal phenotype of the various /d alleles is quite variable (Maas et al., 1994) and renal involvement was only seen rarely in our mice. Although we have not performed a quantitative assessment of the ability of these mice to breed, we have had no trouble maintaining the line as homozygotes, indicating reproductive suitability of both male and female mutants. Additionally, when we have performed heterozygote $x$ homozygote crosses, the affected offspring did not seem to have excess mortality compared to their phenotypically normal littermates. Our initial consideration was that this might be due to mixed strain vitality, although we have continued to observe the same viability characteristics in the mice backcrossed for 5 generations into a Balb/c background.

As has been previously observed, the Fmn1 gene does not appear to be essential, since our mice lack this gene in its entirety, spanning from upstream of the gene and including the final exon. In contrast to our observations, two knockout alleles targeting the 5 ' half of the Fmn1 gene (Wynshaw-Boris et al., 1997, Chao et al., 1998) developed renal anomalies, with no limb phenotype. In contrast, an allele leading to deletion of the entire 3' half of the gene (exons 10-24) recapitulated the /dphenotype with much less renal involvement (Zuniga et al., 2004). The findings here and in Zuniga et al. suggest that the renal anomalies observed in the targeted KOs as well as some of the prior $/ d$ alleles may result from a dominant negative effect of the mutant Fmn1 alleles. Because Formin1 itself has a complex transcriptional unit with multiple splice variants (Wang et al., 1997, Chao et al., 1998,), the deletion of portions of the gene might alter the production of downstream isoforms and this may specifically affect the embryonic development of the kidney.

As a side issue, we also note that the predicted gene 4930563P21 is similarly not essential, since it is also completely deleted in our mice. We did not detect expression of this gene in the 4 tissues tested (even in the heterozygous mice), so the validity of this gene prediction is uncertain, despite the fact that it is predicted to encode a 12 exon gene of 307 amino acids. It is possible that this gene is expressed in other tissues or at other times than those examined in this study.

The more interesting finding reported here relates to the effects of the deletion of the Grem1 GCR on the expression of Gremlin1 and, to a lesser extent, on its neighboring genes. As has been observed in many other /dalleles, loss of this GCR leads to a failure of Grem1 expression in the developing limb buds (Fig. 2). Loss of Gremlin production causes failure to establish the Fgf4-Shh signaling feedback loop in the developing limb, as well as outgrowth failure (Haramis et al., 1995, Merino et al., 1999, Zuniga et al., 1999). Our data also suggests that loss of this GCR causes loss of 
Gremlin expression in the kidney, lung and pituitary. However, the transcriptional effects of this GCR are specific for post-natal life, as embryonic expression, at least in the kidney and lung, appears intact. These observations imply that the GCR functions in a tissueand stage-restricted fashion to ensure proper expression in the developing limb bud. The basal promoter for the gene, which has not been characterized, most likely resides in the 5' of the gene and controls expression of Gremlin in the brain. The location of promoter/enhancer elements responsible for embryonic expression of Gremlin in the lungs and kidney may also reside at the 5' end of the gene, although they have not been mapped. This hypothesis is supported by the observation that the $/ d^{\prime n 2}$ allele, which disrupts the relationship between the GCR and the Grem 1 gene without affecting the 5' end, causes only the limb phenotype (Maas et al., 1994).

As a corollary, it is also worthwhile to note that the role of Gremlin in kidney and lung development must be limited to embryonic development, since our mice retain expression in embryos but not in adults. As Gremlin has been reported to be required for branching morphogenesis of the lungs (Shi et al., 2001), it is possible that a similar role is necessary in kidney tubule development; however, once formed, Gremlin function becomes dispensable. This finding has not been previously noted because Grem1KO mice die at birth (Khokha et al., 2003, Michos et al., 2004), with lung failure as part of the reason for mortality (Michos et al., 2004). In addition to the tissue-specific effects of the GCR, our data demonstrate that Grem 1 exhibits sexually dimorphic expression in the pituitary, with high levels of expression only in male mice, which was lost in the mutants. The loss of Grem 1 from the male pituitary does not lead to compromise of the pituitary-gonadal axis, as male mutants are fertile and also does not appear to affect other pituitary functions (e.g., growth).

This study also suggests that loss of the GCR led to changes in the expression of $S g n e 1$ in the pituitary, with female mutant mice exhibiting an increase in expression compared to their phenotypically normal littermates. This observation suggests that the Fmn1Grem 1 GCR may have the ability to function as a tissue-specific transcriptional repressor, although the magnitude of the effect was only on the order of 2.5 -fold. The mechanism of this effect has not been elucidated. It is likely that the changes in message level of Sgne1 are due to the effect of an enhancer acting at a distance. However, we have not excluded the possibility that the effect could occur in trans, e.g., by the production of a microRNA affecting Sgne1 steady state mRNA levels. Expression of this gene in the brain, or in other tissues with much lower levels of expression, did not appear to be affected by this mutation. We also observe the sexually dimorphic expression of the Arhgap11a gene, which is also expressed only in male mice.

In a broader sense, long-range transcriptional control appears to be a common element in limb development. Not only is expression of Gremlin controlled by a distant GCR, but similar findings have long been known for the control of the Hoxgenes, which are expressed in a graded spatial fashion throughout the body, including the limb (Deschamps and van Nes, 2005). Further, transcriptional control of Shh has also been shown to be dependent on an enhancer element located nearly $1 \mathrm{Mb}$ away in the Limb region 1 ( $L m b r l$ ) gene and that disruption at this locus causes the pre-axial polydactyly and the sasquatch phenotype (Lim et al., 2003). This sequence is highly conserved and appears to play a role in limb development from teleost fins up through vertebrate limbs (Sagai et al., 2004) Another transgene-induced limb mutant, doubleridge, characterized by syn- and polydactyly of the forelimb had a similar mechanism of limb defects, as the insertion caused reduced expression of the Wnt pathway inhibitor Dickkopf-1 (Dkk1)(Adamska et al., 2003, MacDonald et al., 2004). Finally, the spontaneous mouse mutation doublefoot exhibits pre-axial polydactyly and head defects (Lyon et al., 1996). Although the causative mutation has not yet been identified, careful genetic mapping has demonstrated that the mutation maps in the region of Indian hedgehog (Ihh)(Hayes etal., 2001); mice with this phenotype have increased activation of Ihh targets (Crick et al., 2003) and it would seem likely that the mutation will be found in a region that affects the expression of $/ h h$, in analogy to many of the mutations described above.

The difficulty in identifying the doublefootmutation highlights the problematic nature of identifying these mutations in the absence of transgene insertions or chromosomal abnormalities. Since the mutation is not located in a coding portion of the gene or in a clearly identifiable promoter region, the absence of a mutation in a structural gene does not rule out a role in causing the genetic defect. The FMN1-GREM1 locus is located at 15q13-q14 in humans, where there are no known limb or renal syndromes mapped (Grzeschik, 2002). Such clinical phenotypes are extremely rare, so that genetic linkage studies are not possible. Many human syndromes might be considered analogous to the /dmutation in mice, including syndromes such as Renal Dysplasia-Limb Defects Syndrome (OMIM 266910), Fibuloulnar Aplasia/Hypoplasia With Renal Abnormalities (OMIM 228940), or Brachydactyly-Ectrodactyly With Fibular Aplasia/Hypoplasia (OMIM 113310) (McKusick, 2003). In fact, any of the human syndromes associated with fibular dysplasia (Lewin and Opitz, 1986), one of the striking features of the $/ d$ mice, might be an analogous human syndrome. The identification of one of these (or other) syndromes as an /danalog would await the identification of a FMN1 or GREM1 mutation in one of these extremely rare patients.

In conclusion, we have identified and characterized a new allele of the /dphenotype. In contrast to other /dalleles and to targeted alleles of $F m n 1$, the mice described here have a complete deletion of the Fmn1 gene along with a neighboring EST of unknown function. These data help to clarify the functional effect of the Fmn1 GCR, indicating that it is essential for the control of Gremlin expression in the developing limb, but that expression in other organs is under the control of other regulatory elements that have yet to be characterized. Unexpectedly, Gremlin exhibits sexually dimorphic expression in the pituitary under the control of the same GCR, but the functional role in this gland is unclear at present. Functionally, Gremlin appears to be required during organogenesis of the kidneys and lungs, but appears to be dispensable for adult function, at least under homeostatic conditions. Finally, although most other genes in the region were unaffected by loss of the GCR, there may be subtle long range effects involving tissuespecific expression of the neighboring Sgne1 gene, although functional consequences are as yet unknown.

\section{Materials and Methods}

\section{Identification of mutant strain}

The $/ d^{1 \text { LSK }}$ strain arose spontaneously during mating of two unrelated heterozygous knockout strains, one carrying a null allele of Pten (Cao et al., 2004) and the other an allele of Prkar1a (Kirschner et al., 2005), neither of which is located on chromosome 2 near the Fmn1-Grem1locus. 
After identification of the phenotype, mice were backcrossed to wild-type littermates to separate the mutation from the other targeted alleles. Once the distinct identity of the phenotype was confirmed, the mutants were backcrossed $\times 5$ generations to BALB/c mice (Harlan). All mice described in this paper were housed in sterile microisolators and handled in accordance with the highest ILACUC standards.

\section{PCR and RT-PCR}

DNA was collected by tail snips from mice and analyzed by PCR using standardized conditions (Kirschner et al., 1999). Polymorphic mouse genomic primers used in the analysis were obtained from the Mouse Genome Informatics website (http://www.informatics.jax.org/). Other primers used for genomic or cDNA amplification are listed in Table 1. For analysis of mRNA samples, tissue was collected from e12.5 embryos (limb buds) or adult mice into Trizol (Invitrogen, Carlsbad, CA). mRNA was prepared according to the manufacturer's recommendations and repurified over RNAeasy columns (Qiagen, Valencia, CA). RNA was reverse transcribed using iScript cDNA synthesis reagents using conditions suggested by the manufacturer (Bio-Rad, Hercules, CA). For semiquantitative experiments, PCR reactions using $1 \mathrm{ul}$ of CDNA were run under standard conditions and resolved in $1.8 \%$ agarose gels. For quantitative experiments, cDNA samples were analyzed in an iCycler using iCycler SYBR green reagents (Bio-Rad). Samples were run in triplicate for each assay and assays were repeated 1-3 times for each sample analyzed. Expression data were pooled for all experiments to derive the data presented. To provide a 'real' expression value for each message and tissue, data were normalized to a relative expression of Gapdh set at 10,000; thus, a relative expression of 1 indicates an expression level $10^{5}$ times lower that than for Gapdh for any given sample. Statistical analysis of the data in Fig. 5 was performed using an unpaired 2-tailed Student's t-test.

\section{Radiology}

For microCT imaging, mice were imaged essentially as described (Powell et al., 2005) by collecting 3602048 x 2048 12-bit projection radiographs at $1^{\circ}$ intervals around the entire specimen (circular data acquisition). These images were collected at $34 \mathrm{kV}, 450 \mu \mathrm{A}$ and 1 ts exposure time with the image intensifier operating in 7 -in. mode. Rendering of the data was performed using VolSuite v3.3 (http://www.osc.edu/ jbryan/VolSuite/index.shtml) using custom adjusted transfer and segmentation functions. For scanning electron micrographs, samples were prepared according to standard methods (Bozzola and Russell, 1999) and imaged using a Philips XL 30 scanning electron microscope equipped with secondary and back-scatter detectors.

\section{Acknowledgements}

The authors would like to acknowledge William H. Towns for expert technical assistance. We would also like to thank Don Stredney and Jason Bryan from the Ohio Supercomputing Center for assistance with image analysis. Portions of this work were supported by grants CA16058 and P20 EB000591.

\section{References}

ADAMSKA, M., MACDONALD, B.T. and MEISLER, M.H. (2003). Doubleridge, a mouse mutant with defective compaction of the apical ectodermal ridge and normal dorsal-ventral patterning of the limb. Dev Bio/255: 350-62.

BOZZOLA, J.J. and RUSSELL, L.D. (1999). Electron microscopy: Principles and techniques for biologists. Jones and Bartlett, Sudbury, MA.

CAO, X., WEI, G., FANG, H., GUO, J., WEINSTEIN, M., MARSH, C.B., OSTROWSKI, M.C. and TRIDANDAPANI, S. (2004). The inositol 3-phosphatase pten negatively regulates fc gamma receptor signaling, but supports toll-like receptor 4 signaling in murine peritoneal macrophages. J Immuno/172: 4851-7.

CAPDEVILA, J., TSUKUI, T., RODRIQUEZ ESTEBAN, C., ZAPPAVIGNA, V. and IZPISUA BELMONTE, J.C. (1999). Control of vertebrate limb outgrowth by the proximal factor meis2 and distal antagonism of bmps by gremlin. $\mathrm{Mo} / \mathrm{Ce} / / 4$ : 83949.

CHAO, C.W., CHAN, D.C., KUO, A. and LEDER, P. (1998). The mouse formin (fmn) gene: Abundant circular rna transcripts and gene-targeted deletion analysis. Mol Med 4: 614-28.

CRICK, A.P., BABBS, C., BROWN, J.M. and MORRISS-KAY, G.M. (2003). Developmental mechanisms underlying polydactyly in the mouse mutant doublefoot. $J$ Anat 202: 21-6.

DESCHAMPS, J. and VAN NES, J. (2005). Developmental regulation of the hox genes during axial morphogenesis in the mouse. Development 132: 2931-42.

GRZESCHIK, K.-H. (2002). Human limb malformations; an approach to the molecular basis of development. Int. J. Dev. Biol. 46: 983-991.

GURRIERI, F., KJAER, K.W., SANGIORGI, E. and NERI, G. (2002). Limb anomalies: Developmental and evolutionary aspects. Am J Med Genet 115: 231-44.

HARAMIS, A.G., BROWN, J.M. and ZELLER, R. (1995). The limb deformity mutation disrupts the shh/fgf-4 feedback loop and regulation of 5 ' hoxd genes during limb pattern formation. Development 121: 4237-45.

HAYES, C., RUMP, A., CADMAN, M.R., HARRISON, M., EVANS, E.P., LYON, M.F., MORRISS-KAY, G.M., ROSENTHAL, A. and BROWN, S.D. (2001). A high-resolution genetic, physical and comparative gene map of the doublefoot (dbf) region of mouse chromosome 1 and the region of conserved synteny on human chromosome 2q35. Genomics 78: 197-205.

IGUCHI, H., CHAN, J.S., SEIDAH, N.G. and CHRETIEN, M. (1984). Tissue distribution and molecular forms of a novel pituitary protein in the rat. Neuroendocrinology 39: 453-8.

KHOKHA, M.K., HSU, D., BRUNET, L.J., DIONNE, M.S. and HARLAND, R.M. (2003). Gremlin is the bmp antagonist required for maintenance of shh and fgf signals during limb patterning. Nat Genet 34: 303-7.

KIRSCHNER, L.S., KUSEWITT, D.F., MATYAKHINA, L., TOWNS, W.H., 2ND, CARNEY, J.A., WESTPHAL, H. and STRATAKIS, C.A. (2005). A mouse model for the carney complex tumor syndrome develops neoplasia in cyclic ampresponsive tissues. Cancer Res 65: 4506-14.

KIRSCHNER, L.S., TAYMANS, S.E., PACK, S., PAK, E., PIKE, B.L., CHANDRASEKHARAPPA, S.C., ZHUANG, Z. and STRATAKIS, C.A. (1999). Genomic mapping of chromosomal region 2p15-p21 (d2s378-d2s391): Integration of genemap'98 within a framework of yeast and bacterial artificial chromosomes. Genomics 62: 21-33.

KLEINEBRECHT, J., SELOW, J. and WINKLER, W. (1982). The mouse mutant limb-deformity (Id). Anat Anz 152: 313-24.

KLEINJAN, D.A. and VAN HEYNINGEN, V. (2005). Long-range control of gene expression: Emerging mechanisms and disruption in disease. Am JHum Genet 76: 8-32.

LEWIN, S.O. and OPITZ, J.M. (1986). Fibular a/hypoplasia: Review and documentation of the fibular developmental field. Am J Med Genet Supp/2: 215-38.

LIM, W., HEARLE, N., SHAH, B., MURDAY, V., HODGSON, S.V., LUCASSEN, A., ECCLES, D., TALBOT, I., NEALE, K., LIM, A.G. et al. (2003). Further observations on lkb1/stk11 status and cancer risk in peutz-jeghers syndrome. $\mathrm{Br} J$ Cancer 89: 308-13.

LU, M.M., YANG, H., ZHANG, L., SHU, W., BLAIR, D.G. and MORRISEY, E.E. (2001). The bone morphogenic protein antagonist gremlin regulates proximaldistal patterning of the lung. Dev Dyn 222: 667-80.

LYON, M.F., QUINNEY, R., GLENISTER, P.H., KERSCHER, S., GUILLOT, P. and BOYD, Y. (1996). Doublefoot: A new mouse mutant affecting development of limbs and head. Genet Res 68: 221-31.

MAAS, R., ELFERING, S., GLASER, T. and JEPEAL, L. (1994). Deficient outgrowth of the ureteric bud underlies the renal agenesis phenotype in mice manifesting the limb deformity (Id) mutation. Dev Dyn 199: 214-28.

MAAS, R.L., ZELLER, R., WOYCHIK, R.P., VOGT, T.F. and LEDER, P. (1990). Disruption of formin-encoding transcripts in two mutant limb deformity alleles. Nature 346: 853-5.

MACDONALD, B.T., ADAMSKA, M. and MEISLER, M.H. (2004). Hypomorphic expression of dkk1 in the doubleridge mouse: Dose dependence and compensatory interactions with Irp6. Development 131: 2543-52.

MARIANI, F.V. and MARTIN, G.R. (2003). Deciphering skeletal patterning: Clues from the limb. Nature 423: 319-25.

MCKUSICK, V.A. (2003). Online Mendelian Inheritance in Man, OMIM (TM). 
McKusick-Nathans Institute of Genetic Medicine, Johns Hopkins University (Baltimore, MD) and National Center for Biotechnology Information, National Library of Medicine (Bethesda, MD).URL http://www.ncbi.nlm.nih.gov/omim. Accessed 17 Feb 2007

MERINO, R., RODRIGUEZ-LEON, J., MACIAS, D., GANAN, Y., ECONOMIDES, A.N. and HURLE, J.M. (1999). The bmp antagonist gremlin regulates outgrowth, chondrogenesis and programmed cell death in the developing limb. Development 126: 5515-22.

MESSING, A., BEHRINGER, R.R., SPLAPAK, J.R., LEMKE, G., PALMITER, R.D. and BRINSTER, R.L. (1990). Insertional mutation at the Id locus (again!) in a line of transgenic mice. Mouse Genome 1990: 107.

MICHOS, O., PANMAN, L., VINTERSTEN, K., BEIER, K., ZELLER, R. and ZUNIGA, A. (2004). Gremlin-mediated bmp antagonism induces the epithelialmesenchymal feedback signaling controlling metanephric kidney and limb organogenesis. Development 131: 3401-10.

MILLS, A.A., ZHENG, B., WANG, X.J., VOGEL, H., ROOP, D.R. and BRADLEY, A. (1999). P63 is a p53 homologue required for limb and epidermal morphogenesis. Nature 398: 708-13.

NISWANDER, L. (2002). Interplay between the molecular signals that control vertebrate limb development. Int J Dev Bio/46: 877-81.

NIEDERMAIER, M., SCHWABE, G.C., FEES, S., HELMRICH, A., BRIESKE, N., SEEMANN, P., HECHT, J., SEITZ, V., STRICKER, S., LESCHIK, G. et al. (2005). An inversion involving the mouse shh locus results in brachydactyly through dysregulation of shh expression. J Clin Invest 115: 900-9.

PAN, Y., LIU, Z., SHEN, J. and KOPAN, R. (2005). Notch1 and 2 cooperate in limb ectoderm to receive an early jagged2 signal regulating interdigital apoptosis. Dev Bio/286: 472-82.

PEARCE, J.J., PENNY, G. and ROSSANT, J. (1999). A mouse cerberus/danrelated gene family. Dev Bio/209: 98-110.

POWELL, K.A., LATSON, L., IBIWOYE, M.O., WOLFMAN, A., GRABINER, M.D., ZBOROWSKI, M., SAKAI, Y. and MIDURA, R.J. (2005). In vivo longitudinal assessment of bone resorption in a fibular osteotomy model using microcomputed tomography. lowa Orthop J25: 123-8.

SAGAI, T., MASUYA, H., TAMURA, M., SHIMIZU, K., YADA, Y., WAKANA, S., GONDO, Y., NODA, T. and SHIROISHI, T. (2004). Phylogenetic conservation of a limb-specific, cis-acting regulator of sonic hedgehog (shh). Mamm Genome 15: 23-34.

SHI, W., ZHAO, J., ANDERSON, K.D. and WARBURTON, D. (2001). Gremlin negatively modulates bmp-4 induction of embryonic mouse lung branching morphogenesis. Am J Physiol Lung Cell Mol Physio/280: L1030-9.

STOPPER, G.F. and WAGNER, G.P. (2005). Of chicken wings and frog legs: A smorgasbord of evolutionary variation in mechanisms of tetrapod limb development. Dev Bio/288: 21-39.

SUN, X., LEWANDOSKI, M., MEYERS, E.N., LIU, Y.H., MAXSON, R.E., JR. and MARTIN, G.R. (2000). Conditional inactivation of fgf4 reveals complexity of signalling during limb bud development. Nat Genet 25: 83-6.

TICKLE, C. (2003). Patterning systems-from one end of the limb to the other. Dev Cel/4: 449-58.

TOPOL, L.Z., MARX, M., LAUGIER, D., BOGDANOVA, N.N., BOUBNOV, N.V., CLAUSEN, P.A., CALOTHY, G. and BLAIR, D.G. (1997). Identification of drm, a novel gene whose expression is suppressed in transformed cells and which can inhibit growth of normal but not transformed cells in culture. Mo/Ce// Bio/17: 4801-10.

WANG, C.C., CHAN, D.C. and LEDER, P. (1997). The mouse formin (fmn) gene: Genomic structure, novel exons and genetic mapping. Genomics 39: 303-11.

WARD-BAILEY, P.F., HARRIS, B.S., DONAHUE, L.R., BRONSON, R.T. and DAVISSON, M.T. (2006). Mutant mouse resource web site, (ed.: The Jackson Labs, Bar Harbor, ME.

WESTPHAL, C.H., MULLER, L., ZHOU, A., ZHU, X., BONNER-WEIR, S., SCHAMBELAN, M., STEINER, D.F., LINDBERG, I. and LEDER, P. (1999). The neuroendocrine protein $7 \mathrm{~b} 2$ is required for peptide hormone processing in vivo and provides a novel mechanism for pituitary cushing's disease. Cel/96: 689700.

WOYCHIK, R.P., GENEROSO, W.M., RUSSELL, L.B., CAIN, K.T., CACHEIRO, N.L., BULTMAN, S.J., SELBY, P.B., DICKINSON, M.E., HOGAN, B.L. and RUTLEDGE, J.C. (1990). Molecular and genetic characterization of a radiationinduced structural rearrangement in mouse chromosome 2 causing mutations at the limb deformity and agouti loci. Proc Nat/ Acad Sci USA 87: 2588-92.

WOYCHIK, R.P., STEWART, T.A., DAVIS, L.G., D'EUSTACHIO, P. and LEDER, $P$. (1985). An inherited limb deformity caused by insertional mutagenesis in a transgenic mouse. Nature 318: 36-40.

WYNSHAW-BORIS, A., RYAN, G., DENG, C.X., CHAN, D.C., JACKSON-GRUSBY, L., LARSON, D., DUNMORE, J.H. and LEDER, P. (1997). The role of a single formin isoform in the limb and renal phenotypes of limb deformity. Mol Med3: 372-84.

YANG, A., SCHWEITZER, R., SUN, D., KAGHAD, M., WALKER, N., BRONSON, R.T., TABIN, C., SHARPE, A., CAPUT, D., CRUM, C. et al. (1999). P63 is essential for regenerative proliferation in limb, craniofacial and epithelial development. Nature 398: 714-8.

ZELLER, R., HARAMIS, A.G., ZUNIGA, A., MCGUIGAN, C., DONO, R., DAVIDSON, G., CHABANIS, S. and GIBSON, T. (1999). Formin defines a large family of morphoregulatory genes and functions in establishment of the polarising region. Cell Tissue Res 296: 85-93.

ZELZER, E. and OLSEN, B.R. (2003). The genetic basis for skeletal diseases. Nature 423: 343-8.

ZUNIGA, A. (2005). Globalisation reaches gene regulation: The case for vertebrate limb development. Curr Opin Genet Dev 15: 403-9.

ZUNIGA, A., HARAMIS, A.P., MCMAHON, A.P. and ZELLER, R. (1999). Signal relay by bmp antagonism controls the shh/fgf4 feedback loop in vertebrate limb buds. Nature 401: 598-602.

ZUNIGA, A., MICHOS, O., SPITZ, F., HARAMIS, A.P., PANMAN, L., GALLI, A., VINTERSTEN, K., KLASEN, C., MANSFIELD, W., KUC, S. et al. (2004). Mouse limb deformity mutations disrupt a global control region within the large regulatory landscape required for gremlin expression. Genes Dev 18: 1553-64.

Received: 21st November 2006 Reviewed by Referees: 22nd January 2007 Modified by Authors and Accepted for Publication: 7th March 2007 Published Online: 14th May 2007 


\title{
Related, previously published Int. J. Dev. Biol. articles
}

See our recent Special Issue on Limb Development edited by Juan Jurlé and Juan Carlos Izpisúa-Belmonte at: http://www.ijdb.ehu.es/web/contents.php?vol=46\&issue $=7$

The expression of Fat-1 cadherin during chick limb development Terence G. Smith, Nick Van Hateren, Cheryll Tickle and Stuart A. Wilson Int. J. Dev. Biol. (2007) 51: 173-176

The expression of Flrt3 during chick limb development Terence G. Smith and Cheryll Tickle Int. J. Dev. Biol. (2006) 50: 701-704

Genetic interaction of Gli3 and Alx4 during limb development Lia Panman, Thijs Drenth, Pascal teWelscher, Aimée Zuniga and Rolf Zeller Int. J. Dev. Biol. (2005) 49: 443-448

Drm/Gremlin, a BMP antagonist, defines the interbud region during feather development. Boris Bardot, Laure Lecoin, Ingrid Fliniaux, Emmanuelle Huillard, Maria Marx and Jean P Viallet Int. J. Dev. Biol. (2004) 48: 149-156

\author{
Evolution of cis-regulatory regions versus codifying regions. \\ Francisco Rodríguez-Trelles, Rosa Tarrío and Francisco J Ayala \\ Int. J. Dev. Biol. (2003) 47: 665-673
}

Identification of cis-elements regulating expression of Fgf10 during limb development. Hidemi Sasak, Takashi Yamaoka, Hideyo Ohuchi, Akihiro Yasue, Tsutomu Nohno, Hirotaka Kawano, Shigeaki Kato, Mitsuo Itakura, Masaru Nagayama and Sumihare Noji Int. J. Dev. Biol. (2002) 46: 963-967

Interactions between FGFs and BMPs in the control of programmed cell death in the developing limb JA Montero, D Macias, Y GananR Merino, J Chimal-Monroy, JM Hurle Int. J. Dev. Biol. (2001) 45: S113-S114

The $35 \mathrm{UZ}$ transposon of Drosophila melanogaster reveals differences in maintenance of transcriptional control between embryonic and larval stages.

F Docquier, N B Randsholt, J Deutsch and P Santamaria Int. J. Dev. Biol. (1999) 43: 275-278

Insertional mutagenesis in transgenic mice generated by the pronuclear microinjection procedure. $\mathrm{R} P$ Woychik and K Alagramam Int. J. Dev. Biol. (1998) 42: 1009-1017

Control of skeletogenesis and programmed cell death in the developing avian limb bud by growth factors. Y Gañan, D Macias, M A Ros, R Merino and J M Hurle Int. J. Dev. Biol. (1996) 40: S189-S189 


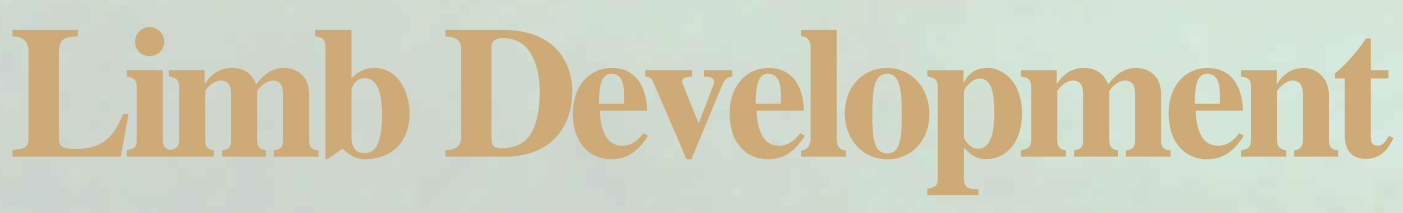

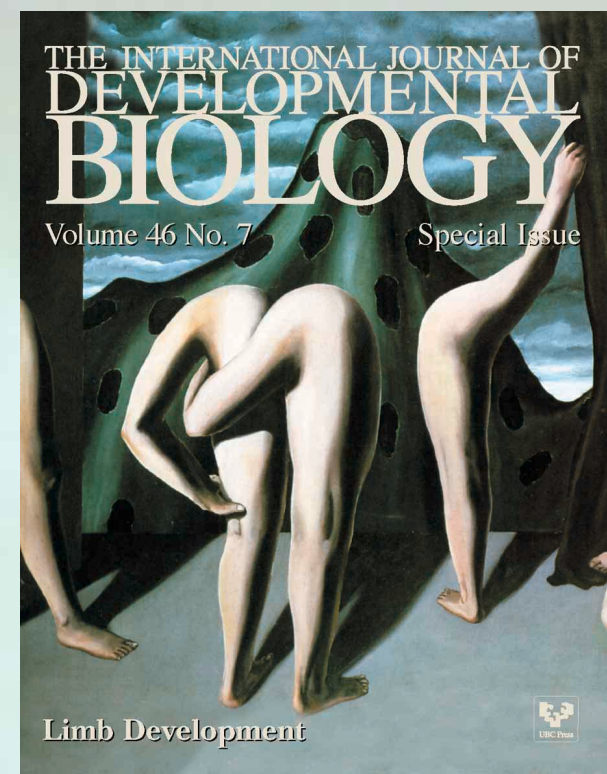

Preface

by Juan M. Hurlé and Juan C. Izpisúa-Belmonte

\section{INTRODUCTORY PAPERS}

Developmental basis of limb evolution

by J. Richard Hinchliffe

The early history of the polarizing region: from classical embryology to molecular biology

by Cheryll Tickle

How serendipity shaped a life; an interview with John W. Saunders, Jr. by John F. Fallon

Positional information in vertebrate limb development; an interview with Lewis Wolpert

by Cheryll Tickle

\section{CONTRIBUTIONS}

The progress zone model for specifying positional information by Lewis Wolpert

Programmed cell death in the developing limb by Vanessa Zuzarte-Luís and Juan M. Hurlé

Interplay between the molecular signals that control vertebrate limb development

by Lee Niswander
Central motif of a magic realist painting portraying animate, isolated limbs as individuals. This picture entitled "Intermission" (1928) was painted by the Belgian surrealist René Magritte (1898-1967). Oil on canvas. Private collection.
Retinoic acid and limb regeneration -a personal view by Malcolm Maden

Vertebrate limb regeneration and the origin of limb stem cells by Susan V. Bryant, Tetsuya Endo and David M. Gardiner

Cell adhesiveness and affinity for limb pattern formation by Hiroshi Yajima, Kenji Hara, Hiroyuki Ide and Koji Tamura

Limb muscle development

by Bodo Christ and Beate Brand-Saberi

Signals regulating muscle formation in the limb during embryonic development by Delphine Duprez

Wnt signalling during limb development

by Vicki L. Church and Philippa Francis-West

Interactions between dorsal-ventral patterning genes Imx1b, engrailed-1 and wnt-7a in the vertebrate limb

by Haixu Chen and Randy L. Johnson

Bmp, Fgf and Wnt signalling in programmed cell death and chondrogenesis during vertebrate limb development: the role of Dickkopf-1

by Lars Grotewold and Ulrich Rüther

Exogenous retinoic acid induces a stage-specific, transient and progressive extension of Sonic hedgehog expression across the pectoral fin bud of Zebrafish

by Lisa Hoffman, Jennifer Miles, Fabien Avaron, Lynda Laforest and Marie-Andrée Akimenko

Distribution and possible function of an Adrenomedullin-like peptide in the developing chick limb bud

by M. Reza Seghatoleslami, Alfredo Martínez, Frank Cuttitta and Robert A. Kosher

Identification of cis-elements regulating expression of Fgf10 during limb development by Hidemi Sasaki, Takashi Yamaoka, Hideyo Ohuchi, Akihiro Yasue, Tsutomu Nohno, Hirotaka Kawano, Shigeaki Kato, Mitsuo Itakura, Masaru Nagayama and Sumihare Noji

Unusual pattern of Sonic hedgehog expression in the polydactylous mouse mutant Hemimelic extra-toes

by Isabelle Blanc, Antoine Bach and Benoît Robert

The mouse polydactylous mutation, luxate (IX), causes anterior shift of the anteroposterior border in the developing hindlimb bud

by Yukari Yada, Shigeru Makino, Sadao Chigusa-Ishiwa and Toshihiko Shiroishi

Human limb malformations; an approach to the molecular basis of development by Karl-Heinz Grzeschik

\section{ORDER FORM}

I would like to order cop(y/ies) of the Int. J. Dev. Biol. Special Issue "Limb Development" (Vol. 46, N 7) at US\$ 90 or Euro $€ 70$ per copy (including post and packaging). Total to be charged: US\$ / Euro $€$ (please specify currency)

\section{ORDER BY}

$\checkmark$ Web: http://www.intjdevbiol.com

$\checkmark$ E-mail: ijdb@ehu.es (include the information indicated above)

$\checkmark$ FAX: +34-94-601-3266

$\checkmark$ POST: to the address shown to the right
The International Journal of Developmental Biology Editorial Office, Uni. of the Basque Country

Dept. Cell Biology and Histology Faculty of Medicine, E-48940 Leioa Vizcaya, SPAIN 